\title{
PANORAMA DE LA AUTOTRADUCCIÓN EN GALICIA. LA ESPECIFICIDAD DEL TRASVASE ENTRE LENGUAS EN CONTACTO EN CONTEXTO DIGLÓSICO
}

\author{
Rexina RodrígueZ Vega \\ Universidade de Vigo \\ xinavega@uvigo.es
}

\begin{abstract}
RESUMEN: En este trabajo ofrecemos una panorámica de la autotraducción en la literatura gallega a partir de 1975. Así, nos acercaremos a la especificidad del contexto cultural y político, los condicionamientos del mercado editorial, el tipo de recepción y las diferentes motivaciones de los autores con el fin de perfilar las características específicas de la autotraducción en una situación de bilingüismo endógeno, una característica que la comunidad gallega comparte con la vasca y catalana.
\end{abstract}

PALABRAS CLAVE: autotraducción; bilingüismo endógeno; diglosia; hibridismo

ABSTRACT: This essay offers a panoramic view of Galician literature since 1975. It analyzes the peculiarities of the cultural and political context, the conditions of the publishing market, and the reception and motivations of various writers in order to outline the concrete characteristics of self-translation within a context of endogenous bilingualism -a feature that Galician society shares with those in the Basque Country and Catalonia.

KEYWORDS: Self-Translation; Endogenous Bilingualism; Diglossia; Hybridism

\section{tow}

\section{LA PENÍNSULA IBÉRICA Y LA AUTOTRADUCCIÓN}

Uno de los fenómenos más curiosos y ricos tanto desde el punto de vista de la traductología como de la sociolingüística y la literatura comparada es, sin duda, el de aquellas versiones llevadas a cabo por los propios autores. El ejer- 
cicio de duplicidad pone en cuestión las fronteras entre original y versión, al tiempo que inscribe en el cuerpo mismo del texto meta las tensiones lingüísticas y culturales a las que está sometido el individuo y, por ende, la sociedad desde la que se crea.

Pese a ello, la autotraducción ha sido considerada hasta fechas relativamente recientes ${ }^{1}$ como un ejercicio raro y poco relevante. De hecho, hay que esperar a los albores del nuevo milenio para que comiencen a aparecer trabajos centrados en el peculiar y, en realidad, dilatado y universal fenómeno de la traducción llevada a cabo por el propio autor. Los estudios, en cierta medida inaugurales, de Brian Fitch (1983) y Michaël Oustinoff (2001) comenzaron por prestar atención a figuras canónicas como Beckett, Nabokov o Julien Green, ejemplos paradigmáticos de escritores en los que la decisión del trasvase lingüístico tiene que ver con motivaciones de carácter individual no asimilables a una pauta sociológicamente significativa. Posteriormente Rainer Grutman (2005) abordó la autotraducción encardinándola en la complejidad multilingüística del ámbito de la francofonía. El enfoque de Grutman pone ya de relieve la especificidad de lo que él denomina "autotraducción vertical" o, lo que es lo mismo, de la lengua dominada a la lengua dominante, habitual en contextos diglósicos (Grutman 2011).

En este sentido, la Península Ibérica, en la que coexisten diferentes sistemas lingüísticos y culturales en un marco plurinacional, ha sido, desde siempre, un escenario privilegiado para el cultivo tanto del bilingüismo de escritura como de la autotraducción. Tal y como indica Julio César Santoyo (2010), la tradición peninsular cuenta entre la abultada nómina de autotraductores ilustres con figuras como Ramon Llull, Enrique de Villena, Antonio de Nebrija o Fray Luis de León. Sin embargo, será a partir de la muerte de Franco cuando esta práctica empiece a tener una altísima frecuencia y sistematicidad. La consolidación de las literaturas catalana, gallega y vasca, amparadas por el nuevo orden democrático, impulsa, paradójicamente, la tendencia a que los autores de estos sistemas periféricos prueben también fortuna en el más amplio mercado de la literatura en castellano. Esta característica específica de las literaturas peninsulares comienza ahora a suscitar el interés de los estudiosos. Así, esta línea de investigación ha dado ya lugar a números monográficos en revistas como Quimera (VV.AA. 2002) y Quaderns. Revista de Traducció (VV. AA. 2009), libros colectivos como Traducción y autotraducción entre las literaturas ibéricas (Gallén 2011) y Aproximaciones a la autotraducción (Dasilva y Tanqueiro 2011) o de manuales como Autotraducció: de la teoria a la práctica de Josep Miquel Ramís (2014).

En este trabajo intentaremos ofrecer una panorámica de la autotraducción en la literatura gallega a partir de 1975. Así, nos acercaremos a la especificidad del contexto cultural y político, los condicionamientos del mercado editorial, el tipo de recepción y las diferentes motivaciones de los autores con el fin de perfilar las características específicas de la autotraducción en una situación de

\footnotetext{
${ }^{1}$ En la actualidad existe ya una muy nutrida bibliografía sobre el tema, como se comprueba en la base de datos permanentemente actualizada que se puede descargar en la siguiente dirección: $<$ http://www.self-translation.blogspot>.
} 
bilingüismo endógeno, una característica que la comunidad gallega comparte con la vasca y catalana.

\section{Lengua y Literatura en Galicia hasta 1975. LoS PRIMEROS AUtotraductores}

Tras un comienzo esplendoroso en el que la lírica galaico-portuguesa se convierte en uno de los referentes literarios indiscutibles de la Europa de la Edad Media y el gallego se afirma en todos los ámbitos, la lengua ve restringido paulatinamente su uso al ámbito de la oralidad. Al margen de episodios esporádicos, habrá que esperar al siglo XIX para que se retome el cultivo literario. De acuerdo con el nacimiento de las reivindicaciones nacionales amparadas por el romanticismo, surge en esta centuria el Rexurdimento (Resurgimiento) que tendrá como figuras centrales a Rosalía de Castro, Eduardo Pondal y Curros Enríquez.

Estos tres poetas, pertenecientes al sector de la burguesía urbana que tenía ya el castellano como lengua de instalación -a pesar de que el conjunto de la población continuaba siendo mayoritariamente monolingüe en gallego-, se iniciarán en la creación literaria alternando las dos lenguas. Así, Rosalía de Castro (1837-1885), reconocida como una de las figuras indiscutibles tanto en poesía como en prosa del siglo xIx español, será considerada también como la escritora central del renacer cultural gallego. Su duplicidad lingüística y cultural - que no le impide, sin embargo, ser consciente de la situación diglósica y, por lo tanto, tomar partido a favor de la reivindicación de la nación marginada- la llevará a ejercer la autotraducción "vertical", de acuerdo con el término acuñado por Grutman (2011), recreando con bastante libertad poemas de su libro gallego Follas novas (1880) al castellano. ${ }^{2}$

También Curros Enríquez (1851-1908), cuya obra es fundamentalmente monolingüe en gallego, autotradujo algunas de sus producciones líricas al casteIlano. En cuanto a Eduardo Pondal (1835-1917), nos encontramos ante una direccionalidad poco frecuente, puesto que traduce del castellano al gallego muchas de las piezas de su obra Rumores de los pinos (1877), publicada como Queixumes dos pinos (1886), obra esta de la que se extrae la letra del himno oficial de la comunidad gallega, lo que da idea de su alto valor simbólico.

A principios del siglo xx, el avance en el reconocimiento político de la realidad nacional gallega dota al idioma de entidades culturales de prestigio como la Real Academia Galega, el Seminario de Estudos Galegos, vinculado a la Universidade de Santiago de Compostela, la revista Nós o las Irmandades da Fala.

La voluntad de consolidación de los usos cultos del idioma mayoritario de la población gallega implica entonces a una buena parte de los intelectuales y creadores del país, que desarrollarán su labor como monolingües en gallego. De esta manera, el idioma vernáculo extiende su campo de acción ya no solo al ámbito literario sino también al ensayo, la obra científica, la oratoria política y el artículo de prensa. Al mismo tiempo, comienzan a aparecer las primeras gramáticas y diccionarios que perfilan la creación de un estándar.

\footnotetext{
2 En concreto "A ventura é traidora" ("Tiembla que una inmensa dicha"), "A xustiza pola man" ("La justicia por la mano") y "Nin ás escuras...!" ("Ni a oscuras"). Cfr. López y Pociña (1999).
} 
En estas primeras décadas del siglo xx el nacionalismo político sitúa como una de sus reivindicaciones fundamentales la devolución a Galicia de sus derechos idiomáticos. Así, en el Estatuto de Autonomía, plebiscitado en junio de 1936, se establece la cooficialidad del gallego y el castellano. La guerra civil trunca esta línea de afirmación cultural y política. Como sucederá con el catalán y el vasco, la primera posguerra supone un silenciamiento casi total de los idiomas minoritarios. La recuperación cultural habrá de esperar hasta la década de los cincuenta en la que el régimen franquista atenúa las medidas represivas, lo que permite empresas como la Editorial Galaxia, que jugará un importante papel en la transmisión del ideario del viejo galleguismo a las nuevas generaciones. También es en esta etapa donde nos encontramos con autotraductores relevantes. Pensemos, por ejemplo, en Álvaro Cunqueiro, autor, como sucede en el caso de Rosalía de Castro, "biliterario", en el sentido dado por Ďurišin (1993), quien así define al escritor que crea para dos literaturas.

Álvaro Cunqueiro (1911-1981), escritor prácticamente monolingüe en gallego en su obra lírica y dramática y claramente bilingüe en el ámbito de la novela y el periodismo literario, presenta la particularidad de haber autotraducido una buena parte de su obra narrativa del gallego al castellano. Podemos citar, entre otros títulos, Merlín e Familia e outras historias (1955)-Merlín y familia (1957), As crónicas do Sochantre (1956)-Las crónicas del Sochantre (1959)³ ${ }^{3}$ Si o vello Sinbad volvese ás illas (1961)-Cuando el viejo Sinbad vuelva a las islas (1962) o Xente de aquí e acolá (1971)-La Otra gente (1975).

Otro de los grandes autores del período que se autotraduce al castellano es Eduardo Blanco Amor (1897-1979). Escritor también "biliterario" en castellano y gallego, Blanco Amor traduce del gallego al castellano obras como A esmorga (1959)-La parranda (1960), Os biosbardos (1962)-Las musarañas (1975) y Xente ao lonxe (1972)-Aquella gente (1976). Sin embargo, como sucedía con Pondal, no será esta la única dirección de su ejercicio de autotraducción, puesto que versiona del castellano al gallego Farsas y autos para títeres (1962)-Farsas para títeres (1976).

La vivencia de la duplicidad resulta de especial interés en estos autores por cuanto reflexionaron abundantemente sobre qué significa el ser un escritor bilingüe en un contexto diglósico. Al margen de las justificaciones de su práctica en relación con cuestiones económicas o de visibilidad, llama la atención su manera de entender la autotraducción como una vía para construir un imaginario alternativo del lenguaje. Así Blanco Amor, en una carta al también escritor gallego Neira Vilas (2010: 58), afirma que "La versión de Os biosbardos ha causado sensación en los lectores en castellano. Ciertamente, por bien del gallego y del castellano, quise que la autotraducción fuese una tercera obra, con los inevitables préstamos de los dos idiomas, pero otra cosa". Posteriormente,

\footnotetext{
3 A pesar de que la edición española presenta a Cunqueiro como único traductor, la correspondencia entre el propio Cunqueiro y Francisco Fernández del Riego -amigo e impulsor de la editorial Galaxia - indica que es este último el responsable del trasvase lingüístico. Con todo, consideramos que el autor participa del proceso, supervisando la versión y proponiendo el añadido del peritexto "Epílogo para Bretones" y ciertas modificaciones en el texto de los Dramatis personae.
} 
en el prólogo a la autotraducción de Farsas para títeres, el escritor indica: "Dentro de mis habituales manejos bilingües, el uso de la lengua nunca me ha sido una duda, una opción. Comienza siéndome una tensión, una decisión seguida valientemente hasta el final" (Blanco Amor 1973: 13). Por su parte, Cunqueiro, interrogado por la académica Elena Quiroga, señala:

Yo soy un escritor bilingüe, en el sentido más extremado del término. Es decir, un bilingüe equilibrado, pero al mismo tiempo con muchas posibilidades de interferencia entre ambos idiomas [...]. Ambos idiomas me son maternos, vernáculos, y debo ejercer una cierta voluntariedad para mantener en solo uno de ellos el libro o el poema que estoy escribiendo. (Quiroga 1984: 22)

En este sentido es también reveladora la respuesta dada por el mismo autor a Alfonso Piñeiro en la entrevista publicada en el Correo Catalán en 1975:

- Las dos lenguas arrastran dos culturas ¿qué significa vivir a caballo de una y otra?

-Yo no creo que se estorben sino que, en realidad, se favorecen.

\section{LA AUtOTRADUCCIÓN EN LOS NARRAdORES GALLEgos A PARTIR DE 1975}

En 1981, años después de terminada la dictadura, se aprueba un nuevo Estatuto de Autonomía de Galicia y en 1983, la Ley de Normalización Lingüística de Galicia, pilares sobre los que se basó el proceso de recuperación y normalización de la lengua gallega. Paralelamente a la legislación reguladora, se llega a la elaboración de un modelo lingüístico que supera las diferencias dialectales. El Instituto da Lingua Galega, creado en 1971, y la Real Academia Galega proponen en 1982 las normas ortográficas y morfológicas de un idioma que hasta entonces pervivía sin estándar. En 1985 inauguran sus emisiones la TVG y la Radio Galega, televisión y radio públicas íntegramente en gallego. Otra de las consecuencias de la ley normalizadora es la implantación del idioma en la enseñanza primaria y secundaria, hecho determinante para el desarrollo del sistema, puesto que el mercado del libro de texto posibilita la creación de nuevas editoriales que acabarán dinamizando extraordinariamente la edición literaria.

El proceso de institucionalización de un campo literario autónomo o, lo que es lo mismo, del paso del nacionalismo literario, marginal y vicario, a la literatura nacional (González-Millán: 2002) hará que prácticamente desaparezca la figura del autor bilingüe. Sin embargo, el reducido tamaño del mercado y la falta de una verdadera profesionalización del mundo editorial llevan a un gran número de escritores, precisamente a aquellos que cuentan con más apoyo de crítica y público, a intentar mayor visibilidad en el ámbito de la lengua castellana a través de la autotraducción.

\subsection{Carlos Casares y Alfredo Conde}

Una de las figuras canónicas del período de los años ochenta y noventa, Carlos Casares (1941-2002), que, además de ser considerado un autor de presti- 
gio, estuvo al frente de instituciones fundamentales para la cultura gallega contemporánea como la Editorial Galaxia o el Consello da Cultura Galega, reconoce la traducción al castellano como una herramienta fundamental para la configuración de un cultura minorizada cuya calidad se define tanto por la de las obras que produce como por su reconocimiento exterior.

Así, interrogado sobre los desafíos que presenta la literatura gallega, el autor responde:

Hai varios problemas. Un deles, que a literatura galega fóra de Galicia practicamente se descoñece, e se a coñecen é a través do castelán. O primeiro paso que dar por un escritor galego é saltar do espazo galego ó español. Necesitas un editor, e non un calquera senón un bo, porque se non tampouco che fai caso ninguén. A partir dese momento xa deches un paso importante, pero a moitos cústalles dalo porque as editoriais están moi metidas no mundo do mercado e apostan case sempre unicamente por libros que teñan moita venda. Isto último tampouco é fácil, porque é algo que non depende só da calidade do libro, senón de moitos factores. O que si é certo é que, por primeira vez, na historia da literatura galega hai bastantes autores galegos traducidos, non só ó castelán senón tamén a outras linguas. Isto é unha novidade absoluta, porque da miña xeración para atrás non hai nada, quitando cousas puntuais. E por iso nunca se estivo tan ben coma agora. (Fortes 2002: 63)

La aguda consciencia de la necesidad de proyección para la afirmación del sistema periférico lleva a Casares a practicar él mismo la autotraducción (Galanes 2014: 183-198) y justifica del siguiente modo esta práctica:

He decidido que de todo lo que escriba haré yo mismo la versión castellana. Creo que la traducción está justificada cuando alguien no conoce el idioma, pero si se conocen los dos, es absurdo buscar un traductor. El mejor traductor es uno mismo. Porque, más que una traducción, lo que haces es otra versión. (Riera 1997: 73)

Otro de los autores consolidados en el inmediato posfranquismo, Alfredo Conde (1945), recurre todavía más sistemáticamente que Casares a la autotraducción como vía de proyección exterior:

Llegado aquí es cuando ya puedo confesar que empecé traduciéndome para hacerme valer como escritor, para poder reconocerme como tal, sabedor que era ya entonces de dos verdades, a saber: que no somos lo que somos, sino lo que nos reconocen que somos, la primera; $y$, la segunda, que una novela que no funciona en otro idioma distinto de aquel en el que fue escrita es porque tampoco lo hace en el original [...]. A mí las mías no me parecían malas, como ya dije antes, y necesitaba constatarlo, sometiéndolas al banco de pruebas de la traducción y de la crítica. Fue así de simple. (Conde 2002: 25)

Un cotejo entre ambas posturas pone de relieve el diferente carácter con el que cada autor aborda su pertenencia a una literatura periférica. En el caso de Casares, el escritor siente la responsabilidad simbólica de ser la voz de una 
nación negada y concibe, por lo tanto, la autotraducción como una vía de mediación efectiva para dar a conocer su cultura: "Síntome escritor dunha lingua minorizada e responsable por iso. Doutra maneira escribiría en castelán [...]. Para min é clarísimo que pertenzo a unha lingua non normalizada, e esa conciencia é a que me inclina a limitarme e a perder oportunidades" (Carballa 1996: 13). La duplicidad lingüística y cultural es planteada, sin embargo, para Alfredo Conde, como una alternativa legítima, sin connotaciones sociolingüísticas o políticas:

Son un escritor galego. Outros son escritores ingleses. Entre eles e mais eu, coma tales escritores, non hai diferencias. Entre a súa fala e a miña tampouco non as hai, máis ca de orde sintáctica, prosódica... e así. [...] O feito de que escriba non quere dicir, nin máis, nin menos ca iso: que escribo en galego. Amén. Non penso nin en salvar a lingua, nin en salvar o país, nin en salvar ningunha outra cousa semellante. Nin sequera a min mesmo, e mira ti que me quero ben. (Conde 1996: 254)

Evidentemente esta postura, que rehúye toda reflexión sobre el conflicto lingüístico e identitario realmente existente, generará un rechazo en la opinión pública gallega (Del Caño 2009). Esto explica la relativamente reciente decisión del escritor, que en una entrevista del 16 de diciembre de 2010 en el diario El Progreso afirmaba: "Deixei de escribir en galego porque me dei de conta de que levaba vinte anos facendo o parvo, de que non se me quere e de que non teño amigos".

\subsection{Manuel Rivas y Suso de Toro}

Durante los años 90 y la primera década del milenio, el mercado editorial gallego conoce una gran desarrollo, así se contabilizan cerca de cincuenta empresas editoras y una frecuencia que llega a sobrepasar los dos mil nuevos títulos por año. En la edición literaria, determinados títulos narrativos pueden alcanzar la cifra de 18.000 ejemplares vendidos. Entre los más leídos figuran dos de los autores monolingües que cuentan también con mayor proyección en el mercado en lengua castellana: Suso de Toro y Manuel Rivas. Ambos escritores ejercen de manera puntual la autotraducción, una práctica que, junto con la presencia habitual como articulistas en la prensa española, les lleva a una continua reflexión sobre su vivencia bilingüe.

En el año 2002 Suso de Toro respondía así a una pregunta acerca de su carácter biliterario:

En relación conmigo hay un tema que sale siempre, el tema de la identidad nacional. Yo sólo digo que soy escritor, ni gallego ni castellano, escritor sin apeIlido. Ahora bien, soy gallego de nación, por origen y por convicción cívica. El gallego es mi idioma nacional, pero al mismo tiempo el castellano es también un idioma mío, con lo cual podría decir que soy español en sentido amplio... (Rodríguez Vega 2002: 58) 
La defensa de la normalidad en la práctica del bilingüismo endógeno, la negación, como en el caso de Alfredo Conde, de la subalternidad que implica el contexto diglósico, es, sin embargo, matizada. Así, la consciencia de ser objeto de una recepción en castellano que tiende a valorarlo como representante de una nación y no como una tendencia del sistema, demuestra, de facto, la existencia de una lectura reductora: "sé que mi obra es recibida en el sistema literario español con un estatuto extraño, ambiguo. Implícita y, a veces, explícitamente se da por entendido que yo no soy de los suyos, yo no soy un escritor español" (Rodríguez Vega 2002: 58).

Pese a ello, vuelve De Toro a incidir en la legitimidad de su doble adscripción, justificándola mediante la mayor calidad de la recepción de su propuesta narrativa. Así observa una tensión, ciertamente paradójica, entre la simplificación exotizante y la mayor profesionalidad del ejercicio de la crítica literaria en el sistema fuerte: "¡Cuando un crítico español me lee, dialoga literariamente con mi texto. Sin embargo, hay también una tendencia a buscar connotaciones tópicas que la literatura gallega tiene para el lector español. Se busca entonces la magia, la antropología...." (Rodríguez Vega 2002: 58).

El cuestionamiento del papel de la crítica en la literatura gallega, un tema que ha hecho correr ríos de tinta tanto en la prensa como en el ámbito académico (González Millán 1996, Vilavedra 2010), manifiesta la debilidad de un sistema literario emergente. La tendencia a la filologización y a la pragmatización de la lectura en aras de un discurso identitario con un gran peso ideológico y resistencial (Figueroa 1988) provoca la desazón en muchos de los autores que ven simplificada u opacada su obra. Al mismo tiempo, es habitual encontrar voces que advierten sobre la existencia de una deriva perversa que se basa en la retroalimentación del sistema cultural gallego a partir del proceso canonizador en la literatura central. El propio De Toro subraya:

Da miña novela Land Rover, teño unha única crítica editada na prensa galega. Teño recensións en francés, en italiano, en español... Pero é que a prensa galega só comezou a falar aquí dela a partir do momento en que foi traducida e editada en español e apareceu reflectida pola prensa española. (Navaza y De Toro, 2001: 69)

Pese a que no se muestra tan pródigo en declaraciones polémicas, también Manuel Rivas defiende la legitimidad de su práctica autotraductora, si bien matiza el coste que le supone este ejercicio de trasvase: "Para mí escribir responde a un deseo y ese impulso lo encuentro en los dos idiomas. Ahora bien, traducir significa, sin lugar a dudas, volver a escribir, y en esa medida representa para mí un riesgo y a veces una insatisfacción volver a internarme en un texto" (Villena 2006). Cabe señalar que ni Suso de Toro ni Manolo Rivas practican la autotraducción con la sistematicidad que sí exhibe Alfredo Conde. Así, Manuel Rivas afirma que "me cuesta mucho ponerme el traje de traductor y por eso me inclino por un profesional que aborde la traducción con más distancia. Desde hace años tengo una gran confianza en Dolores Vilavedra con sus traducciones de mis novelas al castellano" (Villena 2006). 
Pese a las reticencias que manifiesta, Rivas sí ejercerá la autotraducción de los títulos En salvaxe compaña (1993)-En salvaje compañía (1994), Bala perdida (1997)-Bala perdida (1998), A man dos paíños (2000)-La mano del emigrante (2001), As chamadas perdidas (2002)-Las llamadas perdidas, (2003), Muller no baño (2002)-Mujer en el baño (2003) y en algunos de los cuentos que integran el volumen $O$ máis estraño (2011)-Lo más extraño (2011). Debe destacarse también que el autor se vuelve autotraductor -esta vez sí sistemático- en el caso de la poesía El pueblo de la noche y Mohicania revisitada (2005), A desparición da neve-La desaparición de la nieve (2009) o la prosa autobiográfica As voces baixas ( 2012 )-Las voces bajas (2012).

Entre las autotraducciones de Suso de Toro se encuentran: $A$ sombra cazadora (1994)-La sombra cazadora (1995), Conta saldada (1996)-Cuenta saldada (1997), Calzados Lola (1997)-Calzados Lola (1998), Non volvas (2000)-No vuelvas, (2000), Ambulancia (1999)-Ambulancia (2002), Españois todos (2004)-Españoles todos (2004), Outra idea de España (2005) - (Otra idea de España, 2005), Home sen nome (2006)-El hombre sin nombre (2006) ${ }^{4}$, Sete palabras (2009)-Siete palabras, 2010) o Sonámbulos (2014)-Sonámbulos (2014).

La labor autotraductora de Rivas y De Toro difiere, sin embargo, en algunos aspectos fundamentales. En el caso de Rivas se da un consciente trato explicitador al carácter de traducción de la versión española. El título original y el responsable del trasvase así como una contextualización del autor como perteneciente a la literatura gallega aparecen de modo claro en los peritextos. Ese cuidado en la adscripción inicial y en la transparencia de la autotraducción no está presente de igual modo en la edición castellana de las versiones de De Toro.

Preguntado recientemente por la sistemática opacidad de su presentación editorial, el propio De Toro indica:

Un non ten perspectiva sobre un mesmo, pode ser que exista na miña figura algo diso, non o sei. O que sí é certo é que toda a miña obra, ou a maior parte, trata no fondo da identidade persoal. E eu sinto que a miña identidade persoal é lábil, incerta, pode ser que iso me leve a buscar tanto a exposición como o contrario, o ocultamento ou o emboscamento. Non o sei. (Giacomel 2015: 107)

Diferente es también el tipo de autotraducción que presentan ambos autores. Un análisis de la autotraducción de Rivas, En salvaje compañía (Rodríguez Vega 2015b), nos sitúa ante un modelo de autotraducción descentrada, en el que la reproducción de rasgos y normas que reproducen el hibridismo lingüístico de una realidad diglósica como la gallega supone un modo de mediación que visibiliza el conflicto entre lenguas y en la que, por lo tanto, la autotraducción adquiere el carácter de vehículo de afirmación identitaria y resistencia cultural.

Para De Toro, sin embargo, a pesar de incursiones puntuales en la autotraducción recreadora en la que se producen cambios en relación con la diégesis, como sucede en Ambulancia y en La sombra cazadora, prima la tendencia a la

${ }^{4}$ En este caso se trata de una autotraducción compartida con la traductora profesional Belén Fortes. 
literalidad en el trasvase. Tanto es así que al ser interrogado sobre su trabajo, De Toro responde:

\begin{abstract}
A traducción é para min mecánica. De feito non son un bo traductor dos meus textos e teño que corrixilos moitas veces, con frecuencia deslizo galeguismos no texto castelán que debo corrixir logo. No último libro Sonámbulos, na edición en castelán escapóuseme unha frase enteira en galego, a editora pensou que tiña intencionalidade literaria e deixouna pasar tamén. Simplemente é consecuencia dun traballo mecánico. (Giacomel 2015: 104)
\end{abstract}

Pese a sus diferencias, lo cierto es que tanto Rivas como De Toro, escritores profesionales con el gallego como idioma de creación, consiguieron durante los noventa y buena parte de la primera década del nuevo milenio un importante grado de reconocimiento por parte de la literatura dominante. Con todo, desde el imaginario central, siguieron siendo percibidos desde una especie peculiar de extranjería, representantes globales de una literatura periférica que la literatura fuerte acogía en su seno y a la que asignaba una cuota estrictamente delimitada y, a la postre, exotizante.

En un artículo publicado el 20 de noviembre de 1991 en el diario El País, titulado significativamente "Manuel Rivas y Suso de Toro, traducidos al castellano", ambos autores se refieren a esta lectura reductora:

Rivas y De Toro coincidieron en señalar la dificultad de "trascender la literatura gallega al ámbito del idioma castellano". "Es un problema de incomunicación", dijeron, y ambos lamentaron que grandes autores gallegos contemporáneos sean prácticamente desconocidos en el resto de España. Citaron el caso de Con pólvora e magnolia, de Xosé Luis Méndez Ferrín, libro fundamental que continúa sin ser traducido al castellano. "Por eso es necesario reinventar España, para que todo el mundo se sienta más cómodo, y para que nadie nos pregunte nunca jamás por qué escribimos en gallego".

A partir de 2008 la crisis económica y las políticas neoliberales que se pusieron en marcha para paliarla supusieron un punto de inflexión en el diseño plurinacional del estado español. La apertura, siempre insuficiente, hacia los periféricos, cesó de modo abrupto. La supresión de foros de diálogo, la eliminación de espacios culturales en los medios de comunicación, la brutal caída en el mundo de la edición, junto con el recelo, cada vez más evidente, ante los discursos identitarios ligados a reivindicaciones políticas desde el Gobierno del Estado, han ido reduciendo paulatinamente la permeabilidad hacia las culturas cooficiales.

En este contexto, en 2009 Manuel Rivas, edita un poemario en edición cuatrilingüe: A desaparición da neve-La desparició de la neu-Elurraren urtzea-La desaparición de la nieve. En la nota de prensa publicada por El Mundo, podemos leer lo siguiente:

El escritor Manuel Rivas ha creado en su último libro de poemas, La desaparición de la nieve (Alfaguara), un "bosque de la biodiversidad", en el que ha que- 
rido que tengan cabida las cuatro lenguas cooficiales que se hablan en España: el gallego, el euskera, el catalán y el castellano.

Con la traducción de todos los poemas del libro a estas cuatro lenguas, el escritor ha apostado por transgredir límites y fronteras, en un momento en el que "tristemente" se pone el énfasis en los "conflictos", y no en la riqueza que genera la pluralidad lingüística, desde una concepción "sectaria" de la política. (Carrón 2009)

Si Rivas apela al "ecolingüismo" para mantener y proteger la diversidad cultural, Suso de Toro, opta por denunciar abiertamente la cerrazón y el estancamiento y anuncia públicamente su abandono de la escritura de ficción:

Ser un autor en lengua gallega en España significa que no saben lo que hacer contigo, o que sí saben lo que hacer, meterte en la bodega. Yo me sentí muchos años un polizón a bordo de ese barco. Cuando se hablaba de literatura española se podía hablar de un autor peruano o argentino, y yo que soy ciudadano español, que pago los impuestos al Estado español pues por ser autor en lengua gallega no me consideraban parte de la cultura y de la literatura españolas. Acabé hasta los cojones de todo, del sectarismo ideológico y del nacionalismo, del españolismo. (Pais Beiro 2014)

La crisis, económica y cultural, supone, pues, la pérdida de visibilidad de las culturas periféricas en su versión traducida o autotraducida; sin embargo, esta vía de exportación a un mercado que se siente como propio y de cuya aceptación se deriva, como síntoma diglósico, un incremento del valor simbólico y comercial en la literatura de origen no ha dejado de intentarse, hasta el punto de que podemos afirmar que hoy la práctica autotraductora es un hecho habitual en todos aquellos escritores gallegos que consiguen cruzar la frontera interestatal.

\subsection{La multiplicación de autotraductores}

En los últimos años podemos reseñar la práctica autotraductora de narradores como Domingo Villar: Ollos de auga (2006)-Ojos de agua (2006), A praia dos afogados (2009)-La playa de los ahogados (2009); Xurxo Borrazás: Ser ou non (2004)-La aldea muerta (2007); Teresa Moure: Herba moura (2005)-Hierba mora (2007); Ramón Loureiro: As galeras de Normandía (2006)-Las galeras de Normandía (2007); Luís Rei Núñez: O señor Lugrís e a negra sombra (2007)-El señor Lugrís y la negra sombra (2007), Cita en Fisterra (2011)-Cita en Fisterra (2013); Antón Riveiro Coello: As rulas de Bakunin (2000)-Los hijos de Bakunin (2008); Miguel Anxo Murado: Ruído. Relatos de guerra (1995)-Ruido. Relatos de guerra (1997), Fin de século en Palestina (2008)-Fin de siglo en Palestina (2008), O soño da febre (2007)-El sueño de la fiebre (2009); Rexina Vega: Cardume (2007)-Cardumen (2011); Manuel Darriba: O bosque é grande e profundo (2013)-El bosque es grande y profundo (2013); Juan Tallón: Fin de poema (2013)-Fin de poema (2015); Xulia Alonso: Futuro imperfecto (2010)-Futuro imperfecto (2013); Pedro Feijóo: Los hijos del mar (2012)-Os fillos do mar (2013), Morena, perigosa e románica 
(2015)-Morena, peligrosa y románica (2015), A memoria da choiva (2013)-La memoria de la lluvia (2016), Erica Esmorís: O poder de Amábel (2013)-El poder de Amable (2013) o Ledicia Costas: Escarlatina, A cociñeira defunta (2014)-Escarlatina, la cocinera cadáver (2015).

Como podemos comprobar, el recurso a la autotraducción dista de ser un hecho aislado en el presente literario. La gran mayoría de estas autotraducciones es transparente, es decir, explícita en los peritextos, sin embargo, podemos observar un tratamiento diferenciado a la hora de poner el énfasis en la visibilidad de la cultura de origen.

Por una parte, tenemos a aquellos autores que publican en editoriales de gran tirada en cuya promoción se busca acceder al gran público incidiendo en la galleguidad del mundo diegético que presentan. Así, por ejemplo, Espasa promociona la obra Los hijos del mar, de Pedro Feijoo, relacionando a este autor tanto con Domingo Villar como con Manuel Rivas, representantes de una realidad nacional exotizada que consigue atraer a un gran número de lectores: "Primero fue Manuel Rivas, luego leímos a Domingo Villar. Ahora llega Pedro Feijoo, la nueva sensación literaria de Galicia". ${ }^{5}$

Esa lectura reductora, que identifica al autor con el país y no con una tendencia del sistema se puede observar con claridad en las críticas publicadas en los blogs literarios. Veamos, por ejemplo, la recensión de "Un lector indiscreto" que, debido a su origen gallego, se erige como intermediario:

Los hijos del mar es una novela gallega cien por cien. No solo porque los hechos transcurran en Vigo, sino también por el lenguaje que utiliza el autor a la hora de narrarlos. Su estilo es directo y utiliza un lenguaje sencillo cargado de ironía y de nuestra típica retranca, utilizada sobre todo por el arquitecto, lo que hace que nos provoque alguna sonrisa. Todo ello ayuda a que la novela sea de fácil lectura y nos invite a seguir leyendo. Un gran acierto el dar a conocer a Pedro Feijoo y su novela al resto del país. Solo me queda invitar a que la lean y verán cómo les entrarán ganas de conocer la ciudad olívica y los bellos parajes que hay en las islas que se mencionan en ella. (Portela 2013)

Como podemos comprobar, persiste la reducción etnográfica y exotizadora contra la que había reaccionado sistemáticamente en el franquismo Álvaro Cunqueiro en sus declaraciones en prensa (Rodríguez Vega 2001) y, ya en democracia avanzada, Suso de Toro:

Tenemos previamente asignada una cuota [políticamente correcta para las literaturas peninsulares de expresión no castellana] que normalmente es un autor y si hay suerte son dos, como es el caso de la literatura gallega con Manolo Rivas y conmigo. Hay un juego que no es lógico porque yo creo que el sistema literario debe regirse por criterios estrictamente literarios. Un ciudadano que escribe literatura en una lengua del Estado español es simplemente un escritor como todos los demás. (Rodríguez Vega 2002: 58)

5 <http://www.planetadelibros.com/libro-los-hijos-del-mar/92555>. 
Sin embargo, junto a esa tendencia pertinaz, aparecen ahora otro tipo de empresas editoriales que, desde Galicia, buscan visibilizar a la cultura minorizada en la cultura dominante de acuerdo con criterios, como pedía Suso de Toro, estrictamente literarios. Este es el caso, por ejemplo de Mar Maior, el sello creado en 2014 por la Editorial Galaxia y que se concibe como una plataforma de difusión de la literatura gallega en diferentes ámbitos lingüísticos: castellano, portugués, inglés y alemán. El sello debuta con la versión al castellano, realizada por un traductor profesional o por el propio autor, como es el caso de Xulia Alonso, ya citado. La creación de abundantes paratextos por parte de la editorial pretende guiar una correcta contextualización del discurso crítico en la literatura meta.

Se da, pues, por vez primera, una operación de exportación al mercado castellano que busca delimitar con claridad el carácter "traducido" de las obras gallegas. Frente a la labilidad que había caracterizado hasta ahora la recepción en la literatura castellana de autores gallegos, cuya adscripción inicial bien se minimizaba o invisibilizaba, bien se hipertrofiaba hasta al punto de contemplar al autor como representante global de la cultura minorizada, ahora se busca incidir tanto en la tradición, normas y valores propios del sistema gallego como en la especificidad de las propuestas literarias de los autores.

Otro de los sellos de reciente aparición es Pulp Books de la editorial Rinoceronte:

La humanidad nos estará agradecida por haber creado cosas como la empanada de berberechos, pero Galicia tiene más que ofrecer: una cantera de autores que desde los años 80 ha despuntado con textos narrativos de gran calidad. En el nuevo siglo se ha incorporado a las letras gallegas una amplia nómina de jóvenes escritores que tienen mucho que decir, desde la periferia hacia el mundo.

La selección de Pulp Books ofrece algunas de las obras más recientes de la literatura gallega contemporánea: obras publicadas originalmente en gallego, reconocidas por la crítica, por el público y por los premios más prestigiosos, y que ahora presentamos en traducción al castellano, catalán y euskera. Pero queremos atravesar los Pirineos, con traducciones al alemán, italiano y japonés de algunos de nuestros títulos.

¿Literatura nórdica? ¡Desde luego! Pero del norte de España. Un exotismo cercano, familiar, que le mostrará al público lector hispano una ficción menos conocida de lo que debería. Tan cerca, tan lejos. ${ }^{6}$

Esta presentación editorial coincide en sus objetivos básicos con la del sello Mar Maior: una plataforma de difusión de la literatura gallega en diferentes ámbitos lingüístico-culturales. También, como en el caso de Mar Maior, nos encontramos ante la primera fase de esa proyección: ${ }^{7}$ la traducción al mercado más próximo, si bien ambas difieren por cuanto Mar Maior se centra únicamente en la versión castellana y Pulp Books inicia un proceso de exportación que engloba a todas las literaturas nacionales que conviven en el marco estatal. Con todo y

\footnotetext{
${ }^{6}<$ http://www.pulpbooks.es/pulp.php>.

7 De momento, en el catálogo de la editora figura la traducción de un único libro, Dime algo sucio, de Diego Ameixeiras, al italiano y al alemán.
} 
pese a la voluntad de evitar los prejuicios diglósicos, situándose en pie de igualdad con otras literaturas, la redacción editorial incide en el "exotismo cercano" como un grado peculiar de extranjería, lo que indica la complejidad del espacio peninsular configurado, de hecho como una "comunidad interliteraria" (Ďurišin 1993) con relaciones asimétricas.

En cuanto al aspecto específico del tratamiento de la autotraducción, vemos cómo Mar Maior minimiza este fenómeno, presentando de modo idéntico traducciones alógrafas y traducciones de autor. En lo que se refiere a Pulp Books encontramos una toma de postura editorial. Moisés Rodríguez Barcia, responsable del sello, indica: "opinamos que os escritores galegos deben seguir escribindo en galego e que poden e deben ser traducidos por tradutores ao castelán e outros idiomas, como facemos nós no noso selo Pulp Books" (Giacomel 2015: 45).

La postura contraria a la traducción del propio autor es hoy frecuente en el panorama gallego. En esta consideración pesan tanto factores estrictamente ligados a la profesionalidad del ejercicio de traslación idiomática como a aspectos de carácter sociolingüístico. Así, desde este punto de vista, la autotraducción es percibida como una actividad diglósica.

Esa es la opinión que defiende, entre otros, Xosé Manuel Dasilva (2009)، quien advierte del peligro de la invisibilización de la nacionalidad literaria del escritor, fagocitado por el sistema dominante.

Interrogado sobre si es el autor la persona más idónea para traducir sus obras, el crítico literario gallego César Lorenzo Gil responde:

Desde o meu punto de vista, non. Menos cando son autores perfectamente bilingües. Coido que, tal e como xa se estudou, en moitas ocasións non se dan procesos de tradución senón de adaptación, incluso de reescritura das obras orixinais. Isto fructifica en cuestións moi apetitosas desde o punto de vista da análise crítica, o estudo sociolingüístico e a teoría literaria pero crea inestabilidade sobre esa autosuficiencia do sistema literario galego da que antes falaba. A escrita e a tradución son elementos próximos pero penso que non son equivalentes. A tradución debera estar nas mans de alguén que non poida usar o texto coa liberdade que os autores se permiten. (Giacomel 2015: 45)

En la consideración de la autotraducción como "traición" a la cultura de origen, estudiosos como Dasilva (2009) citan los preconceptos, claramente diglósicos, que los autores aducen para "justificar" su práctica. Así, tal y como hemos visto más arriba, los casos de Alfredo Conde y Suso de Toro resultan paradigmáticos por cuanto justifican la traducción al español como prueba de la calidad del texto (Conde) o como vía para encontrar recepción crítica (De Toro).

Otro de los factores que actualmente se consideran como elementos de distorsión que perjudican enormemente a la literatura débil es el ejercicio de la autotraducción simultánea, lo que implica la existencia de una doble versión lingüística en el mercado periférico que acaba por perjudicar a una industria editorial cada vez más débil y con menores oportunidades de difusión. 
Sea como fuere, lo cierto es que la autotraducción sigue siendo una práctica habitual en las letras gallegas contemporáneas. Frente a otras épocas recientes en las que, como hemos visto en los casos de Eduardo Blanco Amor, Álvaro Cunqueiro o Manuel Rivas, se buscaba conscientemente en la operación de trasvase una mediación cultural que diese a conocer la identidad periférica, en la actualidad la tendencia lleva a intentar borrar las referencias locales dentro de una estrategia de uniformización globalizadora. La reciente proliferación de nuevas voces en un sistema literario como el gallego, fuertemente atacado por la crisis económica y la política recentralizadora tanto del Gobierno central como del autonómico, junto con la aparición de una miríada de nuevas empresas de pequeño tamaño en el mercado de la edición en español están propiciando que la traducción de autor se incremente sin el plus de reivindicación identitaria que visbilizaría la autonomía del campo cultural en el que esas obras tienen origen. Teniendo en cuenta este estado de cosas, no es de extrañar que sea la versión castellana la que acabe imponiéndose como texto puente para la conquista de otros mercados extraestatales.

\section{Algunas consideraciones finales Sobre La ESPECIFICIDAD DE LA aUtotraduc- CIÓN INTRAESTATAL EN EL CONTEXTO PENINSULAR}

Si tenemos en cuenta la implicación de la situación sociolingüística tanto en el proceso como en el producto de la autotraducción, la oposición entre la autotraducción "intraestatal" y la autotraducción "interestatal" se revela como una distinción de primer orden para dar cuenta de la especificidad del contexto peninsular.

La aplicación de esta clasificación permite oponer al escritor que se autotraduce dentro de su propio país y a aquel que lo hace en un país extranjero o, lo que es lo mismo, al escritor diglósico frente al bilingüe. La tesis defendida por Ramis (2014) y que sigue los estudios previos de Lagarde (2001) o Grutman (2005; $2011 ; 2012$ ) incide en el hecho de que la decisión de traducir de la lengua dominada a la lengua dominante obedece a menudo a una imposición de carácter social. Esta imposición puede suponer la marginalización de la propia lengua en la medida en la que el nuevo texto es fagocitado por la cultura dominada o hegemónica. Ante esta situación la actitud que mantiene el autotraductor respecto a las relaciones de poder resulta básica para que esta marginalización se acentúe o se atenúe. La ocultación o explicitación, tanto en el texto como en los paratextos del origen lingüístico supone una elección consciente, una toma de posición. La presión del mercado de la lengua dominante tenderá invariablemente a querer presentar como original lo que es producto de una autotraducción y, por lo tanto, a visibilizar al autor al tiempo que invisibiliza a la literatura dominada; sin embargo, ante esta situación el autor puede también optar por reivindicar abiertamente su comunidad lingüística y literaria de origen. La autotraducción hacia un sistema fuerte supondría en este caso una lucha por la visibilidad tanto del texto como de la cultura dominada. Esta última posibilidad es, sin embargo, habitualmente puesta en cuestión por los diferentes agentes culturales que ven en 
esta práctica ante todo una manifestación de esquizofrenia lingüística y cultural que sitúa al autor en una "tierra de nadie". Así, entre las consecuencias que se perciben en la práctica se tienden a subrayar los problemas en las interferencias de códigos, en la consideración individual del autor, considerado traidor a su comunidad y relativamente extraño en la comunidad de acogida, y, en general, en la marginalización del conjunto de su literatura de origen.

En cuanto a las motivaciones personales para abordar una autotraducción, se observan, además del deseo de mayor visibilidad y lucro, el control del proceso de trasvase, la posibilidad de efectuar correcciones tanto de errores puntuales como de aspectos estilísticos e incluso de continuar el proceso creativo, ampliando o haciendo evolucionar la obra. La visión general de la autotraducción como un amplio proceso de mejora de la obra -olvidando quizás que en ocasiones la tendencia a la sobreescritura o a la literaturización inflacionaria actúan como factores deformantes- implica también serios interrogantes en relación con el estatuto de la nueva versión. Así, el enfoque de Fich y Oustinoff lleva a considerar como texto definitivo bien el conjunto de ambas versiones, bien la más reciente, entendida como la última de una serie de variantes. Sin embargo, el estudio detenido de autotraducciones recreadoras como las de Álvaro Cunqueiro (Rodríguez Vega 2015a), por ejemplo, nos lleva a cuestionar la concepción de la versión bien como texto jerárquicamente superior bien como "segundo original", puesto que concebir el texto de partida y el de llegada como variantes no intercambiables de un único texto hipotético minimiza las características estrictamente ligadas tanto a esa enunciación segunda, propia de la traducción, como al ejercicio parcial de deriva hipertextual que supone la recreación. Parece, pues, pertinente establecer una escala que, sin olvidar la necesidad de contemplar el conjunto de las variantes, distinga la coherencia interna del primer original. Probablemente esta característica se manifieste no solo en las autotraducciones de Cunqueiro sino, en general, en las de la mayoría de escritores peninsulares en situación de bilingüismo endógeno. La asunción de la bicefalia, sitúa pues a obras realizadas, no lo olvidemos, "río arriba", desde una clara situación de diglosia que evidencia una "subordinación colonial" (Casanova 2002) en un "sistema intermediario" (Lambert 1987) que, al potenciar la interferencia de elementos entre dos literaturas, dificulta extraordinariamente la determinación misma del estatuto de ambos textos y, por lo tanto, su recepción. Las autotraducciones de las literaturas cooficiales vendrían, pues, a reclamar una concepción del espacio literario peninsular, marcado tradicionalmente por una concepción en exceso rígida de las fronteras lingüísticas y políticas, como un ámbito más amplio y complejo.

\section{OBRAS CITADAS}

Blanco Amor, Eduardo (1973): Farsas para títeres. Sada, Ediciós do Castro.

Carballa, Xan (1996): "Carlos Casares", A Nosa Terra, n. ${ }^{\circ}$ 720, pp. 12-13.

Carrón, Concha (2009): "Manuel Rivas publica La desaparición de la nieve". En: <http:// www.elmundo.es/elmundo/2009/04/14/cultura/1239722042.html4/14/2009> [última visita 07.02.2016]. 
Casanova, Pascale (2002): "Consécration et accumulation de capital littéraire. La traduction comme échange inégal", Actes de la recherche en sciences sociales, vol. 144, n. ${ }^{\circ} 2$, pp. 7-20.

Conde, Alfredo (1996): "Autopoética", Boletín Galego de Literatura, n. ${ }^{\circ}$ 15-16, pp. 253-257.

_- (2002): "La autotraducción como creación", Quimera, n. ${ }^{\circ} 210$, pp. 20-26.

- (2010): <http://galiciae.com/noticia/79996/deje-de-escribir-en-gallego-porque-repare-en-que-llevaba-20-anos-haciendo-el-tonto> [última visita 07.02.2016].

Dasilva, Xosé Manuel (2009): "Autotraducirse en Galicia: ¿bilingüismo o diglosia?", Quaderns: Revista de traducció, n. ${ }^{\circ} 16$, pp. 143-156

Dasilva, Xosé Manuel, y Tanqueiro, Helena (eds.). (2011): Aproximaciones a la autotraducción. Vigo, Academia del Hispanismo

Del Caño, Xosé Manuel (2009): Conversas con Alfredo Conde. Xuízo, sentenza e condena. Vigo, Ir Indo.

Ďurišin, Dionýz (1993): Notions et principes. Trad. Alena Anettova. Vol. 6 de Communautés interlittéraires spécifiques. Bratislava, Académie Slovaque des Sciences.

El País (1991): "Manuel Rivas y Suso de Toro, traducidos al castellano", 22 de noviembre.

Figueroa, Antón (1988): Diglosia e texto. Vigo, Edicións Xerais.

Fitch, Brian T. (1983): "L'intertextualité interlinguistique de Beckett: la problématique de la traduction de soi", Texte, n. ${ }^{\circ} 2$, pp. 85-100.

Fortes López, Belén (2002): "Carlos Casares, palabra de escritor", Tempos Novos, n. ${ }^{\circ}$ 56, pp. 60-66.

Galanes, lolanda (2014): "Carlos Casares y la traducción: obra dispersa e inédita", Quaderns. Revista de Traducció, n. ${ }^{\circ}$ 21, pp. 183-198.

Gallén, Enric et al. (eds.) (2011): Traducción y autotraducción en las literaturas ibéricas. Berna/Berlín, Peter Lang.

Giacomel, Giada (2015): La autotraducción entre castellano y gallego: "A Esmorga" y "La parranda" de Eduardo Blanco Amor, obras en comparación. Tesis de licenciatura. Disponible en <http://tesi.cab.unipd.it/49943/1/GIADA_GIACOMEL_2015.pdf> [última visita 07.02.2016].

González Millán, Xoán (1996): A narrativa galega actual (1975-1984). Unha historia social. Vigo, Xerais.

— (2002): "Nacionalismo literario y teoría del campo literario: la experiencia gallega de las últimas décadas". En: Silvia Bermúdez, Antonio Cortijo Ocaña y Timothy McGovern (eds.): From Stateless Nations to Postnational Spain / De naciones sin estado a la España postnacional. Boulder, Society of Spanish and Spanish-American Studies, pp. 223-236.

Grutman, Rainier (2005): "La textualisation de la diglossie dans les littératures francophones". En: Jean Morency, Hélène Destrempes, Denise Merkle y Martin Pâquet (eds.) Des cultures en contact. Visions de l'Amérique du Nord francophone. Quebec, Éditions Nota bene.

- (2011): "Diglosia y autotraducción vertical (en y fuera de España)". En: Xosé Manuel Dasilva y Helena Tanqueiro (eds.): Aproximaciones a la traducción. Vigo, Academia del Hispanismo, pp. 69-91. 
(2012): "Traduire I'hétérolinguisme: questions conceptuelles et contextuelles. En: Marie-Annick Montout (dir.): Autour d'Olive Senior: hétérolinguisme et traduction. Angers, Presses de l'Université d'Angers, pp. 49-81.

Lagarde, Christian (2001): Des écritures "bilingües". Sociolinguistique et littérature. París, L'Harmattan.

Lambert, José (1987): “Un modèle descriptif pour l'étude de la littérature. La littérature comme système complexe", Contextos, vol. 5, n. ${ }^{\circ}$ 9, pp. 47-67.

López, Aurora, y Pociña, Andrés (1999): "Sobre as traduccións feitas por Rosalía". En: Rosario Álvarez y Dolores Vilavedra (eds.): Cinguidos por unha arela común. Homenaxe ó profesor Xesús Alonso Montero, vol. 2. Santiago de Compostela, Universidade de Santiago de Compostela, pp. 813-827.

Navaza, Gonzalo, y Toro, Suso de (2001): "A creación literaria como provocación", Tempos Novos. Revista mensual de informacion para o debate, n. ${ }^{\circ} 48$, pp. 66-72.

Neira Vilas, Xosé (2010): Cartas de vellos am igos 1959-1998. Vigo, Galaxia.

Oustinoff, Michael (2001): Bilinguisme d'écriture et auto-traduction. Julien Green, Samuel Beckett, Vladimir Nabokov. París, L'Harmattan.

Pais Beiro, Mario (2014): <http://www.eldiario.es/cultura/Suso-Toro-Espana-nacional-cultura_0_326867743.html> [última visita 07.02.2016].

Piñeiro, Alfonso (1975): "Charla con Álvaro Cunqueiro", Correo Catalán, 3 de agosto.

Portela, Francisco José (2013): <http://unlectorindiscreto.blogspot.com.es/2013/06/loshijos-del-mar-de-pedro-feijoo.html> [última visita 07.02.2016].

Quiroga, Elena (1984): Presencia y ausencia de Alvaro Cunqueiro. Madrid, Publicaciones de la RAE.

Ramis, Josep Miguel (2014): Autotraducció. De la teoria a la pràctica. Vic, Eumo Editorial.

Riera, Miguel (1997): "De lengua, tradiciones literarias y otros Griales", Quimera, n. ${ }^{158-}$ 159, pp. 69-74.

Rodríguez Vega, Rexina (2001): "Estraña ave do paraíso. A recepción da obra cunqueiriana na literatura castelá", Anuario de estudos literarios galegos, n. ${ }^{\circ} 2001$, pp. 201-223.

_ (2002): "La modernidad amordazada de Galicia. Entrevista a Suso de Toro", Quimera, n. ${ }^{\circ} 213$, pp. $56-63$.

— (2015a): "Heterolingüismo y autotraducción. El caso de Álvaro Cunqueiro", Meta: journal des traducteurs / Meta: Translators' Journal, vol. 60, n. ${ }^{\circ}$ 1, pp. 36-52.

— (2015b): "La textualización de la diglosia en las autotraducciones intraestatales. El caso del gallego", Quaderns: Revista de traducció, n. ${ }^{\circ} 22$, pp. 167-180.

Santoyo, Julio César (2010): "Autotraducciones intrapeninsulares: motivos históricos, razones actuales". En: Enric Gallén, Francisco Lafarga y Luis Pegenaute (eds.): Traducción y autotraducción en las literaturas ibéricas. Berna, Peter Lang, pp. 365-380.

Vilavedra, Dolores (2010): A narrativa galega na fin de século. Vigo, Galaxia.

Villena, Miguel Ángel (2006): <http://elpais.com/diario/2006/10/28/babelia/1161992351_ 850215.html> [última visita 07.02.2016].

VV. AA. (2002): Quimera: Revista de literatura. "Autotraducción", n. 210.

VV. AA. (2009): Quaderns. Revista de traducció. "Dossier: L'autotraducció", n. ${ }^{\circ} 16$. 